See discussions, stats, and author profiles for this publication at: https://www.researchgate.net/publication/46645603

\title{
Understanding the involvement of rhizobacteria-mediated induction of systemic resistance in biocontrol of plant diseases
}

Article in Canadian Journal of Plant Pathology · March 2003

DOI: 10.1080/07060660309507043 · Source: OAI

CITATIONS

READS

144

183

4 authors, including:

Peter Bakker

Utrecht University

6 L.X. Ran

237 PUBLICATIONS 11,727 CITATIONS

SEE PROFILE

16 PUBLICATIONS 373 CITATIONS

SEE PROFILE

Corné Pieterse

Utrecht University

396 PUBLICATIONS 30,018 CITATIONS

SEE PROFILE

Some of the authors of this publication are also working on these related projects:

Elucidating composition and functions of the rhizosphere microbiome in response to root exudation. View project

Getting to the root of it: boosting plant health by beneficial root microbes View project 


\title{
Understanding the involvement of rhizobacteria- mediated induction of systemic resistance in biocontrol of plant diseases
}

\author{
P.A.H.M. Bakker, L.X. Ran, C.M.J. Pieterse, and L.C. van Loon
}

\begin{abstract}
Specific strains of nonpathogenic rhizobacteria can induce systemic resistance that is effective against a range of plant pathogens. To exploit induced systemic resistance, detailed knowledge of the triggering bacterial traits involved and on signal transduction pathways in the plant is necessary. Possibilities to improve effectiveness of induced resistance by rhizobacterial strains are discussed.
\end{abstract}

Key words: induced systemic resistance, lipopolysaccharides, Pseudomonas fluorescens, Pseudomonas putida, salicylic acid, siderophores, signaling pathways.

Résumé : Des souches spécifiques de rhizobactéries non pathogènes peuvent induire, chez les plantes, une résistance systémique efficace contre un ensemble d'agents pathogènes. Afin de pouvoir tirer profit de la résistance systémique induite, une connaissance détaillée des caractéristiques bactériennes liées au déclenchement et des voies de transmission du signal dans la plante est nécessaire. Les possibilités d'amélioration de l'efficacité de la résistance induite par des souches rhizobactériennes sont discutées.

Mots clés : résistance systémique induite, lipopolysaccharides, Pseudomonas fluorescens, Pseudomonas putida, acide salicylique, sidérophores, voies de signalisation.

\section{Introduction}

The estimated number of prokaryotic cells in our planet's soil is $2.6 \times 10^{29}$, providing an enormous capacity for genetic diversity (Whitman et al. 1998) and a great potential for exploitation. One of the uses of prokaryotes from soil is for biological control of soilborne plant diseases (Handelsman and Stabb 1996). Particularly, strains of plantroot-inhabiting fluorescent Pseudomonas spp. have been studied in detail for their disease suppressive properties. In a recent review, Weller et al. (2002) described the importance of these bacteria in soil suppressiveness against Gaeumannomyces graminis (Sacc.) Arx. \& D. Olivier var. tritici J. Walker. Active and long-term colonization of the root surface of the plant (Lugtenberg et al. 2001), and effective expression of disease-suppressive traits (Handelsman and Stabb 1996), are generally considered prerequisites for successful suppression of soilborne diseases by rhizobacteria. The mechanisms involved in disease suppression

Accepted 2 January 2003.

P.A.H.M. Bakker, ${ }^{1}$ L.X. Ran, ${ }^{2}$ C.M.J. Pieterse, and L.C. van Loon. Section of Phytopathology, Institute of Biology, Utrecht University, P.O. Box 800.84, 3508TB Utrecht, Netherlands.

${ }^{1}$ P.A.H.M.Bakker@bio.uu.nl

${ }^{2}$ Present address: Central South Forestry College, Zhuzhou, Hunan, People's Republic of China. are diverse and include competition for iron, production of antibiotics, and induction of systemic resistance (Handelsman and Stabb 1996).

\section{Induced systemic resistance}

Induced resistance is a state of enhanced defensive capacity developed by a plant when appropriately stimulated (van Loon et al. 1998). In 1991, two research groups independently described induced systemic resistance (ISR) as the mode of action of disease suppression by nonpathogenic rhizosphere bacteria (Van Peer et al. 1991; Wei et al. 1991). Since then, the involvement of ISR in disease suppression has been studied for a wide range of biological control microorganisms and, in many cases, ISR was found to be involved. Phenotypically, ISR is similar to systemic acquired resistance (SAR) that is triggered by necrotizing pathogens. Although the terms SAR and ISR are synonymous, for convenience in the present study, we wish to distinguish between pathogen- and rhizobacteria-induced resistance, by using SAR for the pathogen-induced type and ISR for the rhizobacteria-induced type. Whereas SAR requires accumulation of salicylic acid (SA) in the plant (Sticher et al. 1997), in Arabidopsis thaliana (L.) Heynh., ISR does not and, instead, is dependent on intact responses to ethylene and jasmonic acid (JA) (Pieterse et al. 1998). When these different signal transduction pathways are triggered simulta- 
neously in $A$. thaliana, disease suppression is enhanced (Van Wees et al. 2000). This suggests that combining bacterial traits that trigger either the SA-, or the ethylene- or JA-dependent response can improve biological control. Elucidating the nature of bacterial triggers of the different pathways will enable us to utilize ISR in a sensible way.

\section{Distinguishing between ISR and direct effects}

Arabidopsis mutants that are insensitive to ethylene (etrl) or JA (jarl) and the Arabidopsis mutant expressing no pathogenesis-related proteins for resistance to Pseudomonas (nprl) do not express ISR after treatment with Pseudomonas fluorescens Migula WCS417r (Pieterse et al. 1998). Use of the etrl, jarl, and nprl mutants can enable us to determine whether direct interactions between biocontrol agents and the pathogen are effective in disease suppression. When the biocontrol bacteria and the pathogen are coinoculated into the rhizospheres of these mutants, there will be protection only if the bacteria can directly inhibit the development of the pathogen. When the bacteria fail to suppress disease in the mutants, but are effective on the wild-type plants, ISR must be the main mode of action.

\section{Role of salicylic acid}

A rhizobacterial metabolite that was suggested to trigger the SA-dependent signal transduction pathway is SA itself (De Meyer and Höfte 1997; Leeman et al. 1996; Maurhofer et al. 1998). Salicylic acid production has been observed for several bacterial strains, and exogenously applied SA can induce resistance in many plant species. For example, $P$. fluorescens strain WCS374 produces relatively large quantities of SA under conditions of iron limitation. Moreover, WCS374 is more effective, in radish, in ISR against fusarium wilt under iron-limited conditions compared with conditions of sufficient iron availability (Leeman et al. 1995). Pseudobactin siderophores, low-molecular-weight molecules, are also produced by WCS374 under iron-limited conditions. However, a pseudobactin mutant of WCS374 was as effective as the parental strain in disease suppression. Therefore, it was concluded that SA was probably responsible for the increased effectiveness of WCS374 under conditions of iron limitation. However, no indications for activation of SAdependent signaling in radish after WCS374 treatment were observed (Hoffland et al. 1995). Moreover, treatment with strain WCS374 cannot induce systemic resistance in A. thaliana, whereas the application of SA does (Van Wees et al. 1997). Possibly, the iron-regulated ISR by WCS374 in radish is mediated by the SA-containing siderophore pseudomonine (Mercado-Blanco et al. 2001). Pseudomonine is a nonfluorescent siderophore, produced by WCS374, that was discovered when analyzing nonfluorescent mutants of this strain (Figs. 1 and 2). Whether pseudomonine is active in ISR remains to be elucidated. The plant-root-colonizing Pseudomonas aeruginosa (Schroeter) Migula strain 7NSK2 induces resistance in tobacco, bean, and tomato. Its ability of ISR has been linked to production of SA (De Meyer and Höfte 1997). However, recent evidence strongly suggests that SA is not the inducing compound from 7NSK2, but that the compounds pyochelin and pyocyanin produced by this strain are a prerequisite for the induction of resistance (Audenaert et al. 2002). It was postulated that 7NSK2 does not produce SA in the rhizosphere, but instead, that the SA is channeled into the siderophore pyochelin (Audenaert et al. 2002). Thus, for several bacterial strains, a role of bacterially produced $\mathrm{SA}$ in induced resistance has been suggested, but upon careful examination, SA seems not to be involved directly (Audenaert et al. 2002; van Loon et al. 1998).

\section{Role of siderophores}

Siderophores are low-molecular-weight molecules that are secreted by microorganisms to take up iron from the environment (Höfte 1993), and their modes of action in suppression of disease were thought to be solely based on competition for iron with the pathogen (Bakker et al. 1993; Duijff et al. 1999; Loper and Buyer 1991). Interestingly, siderophores can induce systemic resistance (ISR) (Leeman et al. 1996). One may therefore consider whether the mode of action of other bacterial metabolites that have been implicated in disease suppression also involves triggering of systemic resistance mediated by rhizobacteria.

\section{Role of antibiotics}

Production of antibiotics has been described as a powerful mode of action in disease suppression by which development and (or) activity of the pathogen is thought to be directly inhibited (Handelsman and Stabb 1996). The involvement of antibiotic production in ISR has not been investigated in detail. However, from studies that utilized strains of pathogens varying in their sensitivity to the antibiotics produced by the biocontrol bacteria, ISR does not seem to be involved. Isolates of $G$. graminis var. tritici that varied in their sensitivity to the antibiotics phenazine-1carboxylic acid and 2,4-diacetylphloroglucinol were also differentially sensitive to biological control by Pseudomonas spp. strains producing these same antibiotics (Mazzola et al. 1995). These results demonstrated that the effect of these antibiotics on the pathogen was direct and not mediated by the plant. However, antibiotics do have direct effects on plants and, therefore, might induce systemic resistance mediated by rhizobacteria. For example, the antibiotics pyoluteorin and 2,4-diacetylphloroglucinol reduced growth of sweet corn, cress, and cucumber (Maurhofer et al. 1992) and, in turn, the stress caused by these antibiotics may also trigger resistance. To further study the possible involvement of antibiotics in ISR, strains of biocontrol bacteria that produce specific antibiotics should be applied spatially separated from the pathogen on the plant surface, to prevent direct interactions between their populations (van Loon et al. 1998). If these strains induce systemic resistance, their mutants lacking antibiotic production should be tested. Conversely, the purified compound can be tested in an experimental setup for resistance induction. 
Fig. 1. Production of fluorescent and nonfluorescent siderophores by fluorescent Pseudomonas spp. Pseudomonas fluorescens WCS374 (1), a nonfluorescent transposon mutant of WCS374 (2), a P. putida strain (3), and its nonfluorescent mutant (4) were grown on King's medium B (King et al. 1954) (A) and on chrome azurol sulfonate (CAS) medium (Schwyn and Neilands 1987) (B). On King's medium B, the pseudobactin-type siderophore fluoresces under UV and, on CAS medium, siderophore activity leads to production of an orange halo. Whereas the nonfluorescent mutant of $P$. putida does not produce a halo on CAS, the mutant of WCS374 still does, suggesting the presence of a second, nonfluorescent siderophore in WCS374.

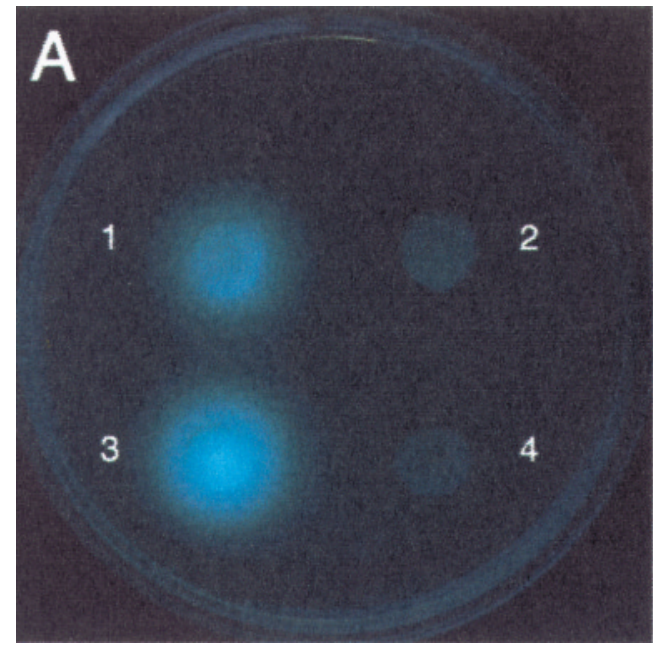

Fig. 2. Structure of pseudomonine, the nonfluorescent siderophore produced by WCS374 (Mercado-Blanco et al. 2001). The molecule contains histamine, a cyclothreonine moiety in the middle, and, interestingly, a SA group. It has been postulated that, in the rhizosphere, WCS374 does not produce $\mathrm{SA}$, but instead, the SA is channeled into pseudomonine.<smiles>CC1ON(CCc2c[nH]cn2)C(=O)C1NC(=O)c1ccccc1O</smiles>

\section{Role of lipopolysaccharides}

Lipopolysaccharides (LPS) have been implicated in ISR triggered by fluorescent pseudomonads in carnation (Van Peer and Schippers 1992), radish (Leeman et al. 1995), and A. thaliana (Van Wees et al. 1997). In the case of ISR against Globodera pallida (Stone) Behrens on potato by Rhizobium etli Segovia et al., the LPS also plays a major role (Reitz et al. 2002). In these studies, either purified LPS was used to induce systemic resistance, or mutants that lack part of the LPS were compared with the parental strain regarding their abilities to induce resistance. Another bacterial determinant that was suggested to be involved in ISR is flagellin, the protein subunit of the flagella.

\section{Research approach}

It appears that in most inducing bacteria, more than one determinant is operative in triggering systemic resistance (ISR) in the plant. The classical approach of studying the mode of action of biocontrol bacteria by generating specific

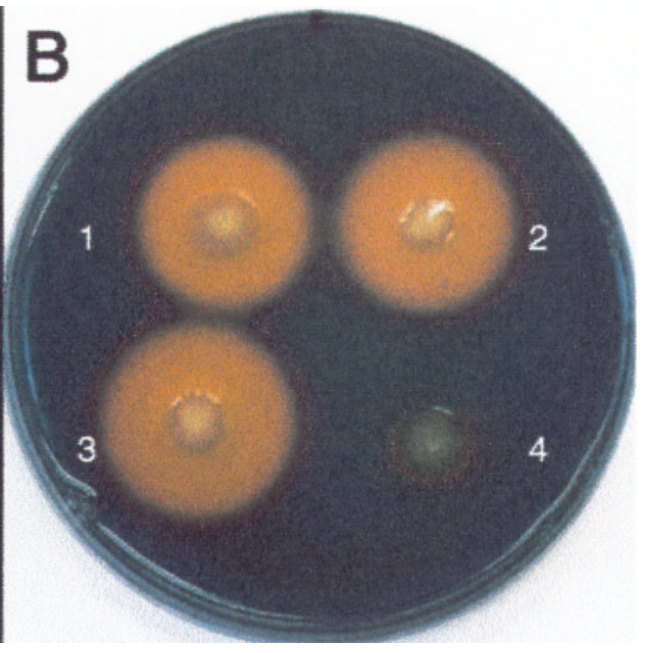

mutants is, therefore, not very informative for studying traits involved in ISR. If one trait is knocked out in the bacterium, the other trait(s) still induce resistance and the mutant is as effective as the parental strain in suppressing disease. In studying induced resistance mediated by $P$. putida WCS358 on A. thaliana, we have experienced this problem. The fluorescent pseudobactin siderophore, the 0antigen of the LPS, and flagellin all induce resistance when they are isolated and applied to the plant roots. Mutants that are defective in one of these three traits are as effective as the parental strain in disease suppression. Even double mutants are still effective in ISR. An alternative approach is to mobilize a gene bank from a strain with ISR ability into a strain with no such ability and, in such a way, identify genes that encode bacterial traits for ISR. Also, the use of indicator plants that contain a reporter gene expressed when ISR occurs would be very helpful in studies for identifying the inducing bacterial determinants. A major problem that has hampered the development of such reporter lines is the lack of known, defense-related genes responding to the bacterial treatments (Van Wees et al. 1999). The development of gene chip technology is a powerful tool to study gene expression patterns in response to ISR. Currently, transcript profiles of Arabidopsis genes are analyzed using DNA microarrays (Pieterse et al. 2002). It appears that several genes are up or down regulated when ISR occurs (B.W.M. Verhagen and C.M.J. Pieterse, personal communication).

\section{Role of population densities}

In a dose-response study of ISR mediated by $P$. fluorescens WCS374 in radish, it was revealed that population densities of $10^{5}$ colony forming units per gram of root are required for significant suppression of disease (Raaijmakers et al. 1995). In situations where no bacteria are introduced, population densities of one single bacterial genotype probably never reach such high densities, making 
it unlikely that, in the field, plants are triggered sufficiently by bacteria to express ISR. Pseudomonas fluorescens strain RS111 and a derivative of this strain, RS111a, have been studied mainly for their abilities to suppress disease when applied in combination with other fluorescent Pseudomonas spp. strains (De Boer et al. 1999). In dose-response studies, it was demonstrated that RS111a was effective in suppressing fusarium wilt of both radish and flax at much lower initial population densities than RS111 (K.C. Zhang, L.C. van Loon, and P.A.H.M. Bakker, unpublished data). Moreover, RS111a suppressed fusarium wilt significantly better than RS111 when applied in a bioassay specific for disease suppression through ISR (De Boer 2000). These results suggest that the level of disease control through ISR by a specific strain can be improved. Further studies to elucidate the determinants of ISR of these strains are ongoing.

\section{Combining mechanisms of disease suppression}

Since ISR and antibiosis seem to be two separate mechanisms of disease suppression by fluorescent pseudomonads, the combination of these modes of action may well lead to improved efficacy of biological control. The antibiosis would first weaken or even partly kill the population of the pathogen and, subsequently, this weakened population would be confronted with a plant that is in a state of enhanced defensive capacity, thus resulting in much less disease development. One could also argue that use of strains that trigger both the JA- or ethylene-dependent and the SAdependent pathway may increase the efficacy of biological control. The latter strategy may require manipulation of bacterial metabolites that trigger the SA-dependent signal transduction pathway. A way to manipulate the production of SA by bacteria such that it can contribute to induction of systemic resistance is to uncouple SA production from the biosynthesis of the SA-containing siderophore. In mutant KMPCH of $P$. aeruginosa 7NSK2, which is unable to synthesize pyochelin and therefore accumulates SA, induction of resistance is indeed mediated by SA (Audenaert et al. 2002). Transfer of the SA-biosynthetic genes of $P$. aeruginosa to $P$. fluorescens strain $\mathrm{P} 3$ led to induced resistance in tobacco against tobacco necrosis virus after treatment with the SA-producing derivative of P3 (Maurhofer et al. 1998). The latter strategy requires use of genetically modified bacteria for field releaseand, before such releases, the impact of the modified bacteria on resident microbial communities has to be examined. It has also been questioned if induced resistance may affect the belowground community of plants (Sonnemann et al. 2002). Use of recently developed techniques that take into account the total microflora, including those that are nonculturable, will be valuable in this respect (Glandorf et al. 2001). Also, the state of enhanced defense capacity may negatively affect plant growth because of fitness costs (Heil 2001). In contrast, a significant growth stimulation was observed in A. thaliana plants treated with the P. fluorescens WCS417r inducing systemic resistance (Pieterse and van Loon 1999).

In conclusion, ISR is a powerful mode of action in biological control of both soilborne and aerial plant diseases. Since ISR by one rhizobacterial strain can be effective against a range of plant pathogens, including bacteria, oomycetes, and fungi (Ton et al. 2002), this technology may contribute significantly to reducing the input of plant protecting chemicals.

\section{References}

Audenaert, K., Pattery, T., Cornelis, P., and Höfte, M. 2002. Induction of systemic resistance to Botrytis cinerea in tomato by Pseudomonas aeruginosa 7NSK2: role of salicylic acid, pyochelin, and pyocyanin. Mol. Plant-Microbe Interact. 15: 1147-1156.

Bakker, P.A.H.M., Raaijmakers, J.M., and Schippers, B. 1993. Role of iron in the suppression of bacterial plant pathogens by fluorescent pseudomonads. In Iron chelation in plants and soil microorganisms. Edited by L.L. Barton and B.C. Hemming. Academic Press, San Diego, Calif. pp. 269-282.

De Boer, M. 2000. Combining Peudomonas strains to improve biological control of fusarium wilt in radish; mechanisms and population dynamics. Ph.D. thesis, Utrecht University, Utrecht, Netherlands.

De Boer, M., Van der Sluis, I., van Loon, L.C., and Bakker, P.A.H.M. 1999. Combining fluorescent Pseudomonas spp. strains to enhance suppression of fusarium wilt of radish. Eur. J. Plant Pathol. 105: 201-210.

De Meyer, G., and Höfte, M. 1997. Salicyclic acid produced by the rhizobacterium Pseudomonas aeruginosa 7NSK2 induces resistance to leaf infection by Botrytis cinerea on bean. Phytopathology, 87: 588-593.

Duijff, B.J., Recorbet, G., Bakker, P.A.H.M., Loper, J.E., and Lemanceau, P. 1999. Microbial antagonism at the root level is involved in the suppression of fusarium wilt by the combination of nonpathogenic Fusarium oxysporum Fo47 and Pseudomonas putida WCS358. Phytopathology, 89: 1073-1079.

Glandorf, D.C.M., Verheggen, P., Jansen, T., Jorritsma, J.W., Smit, E., Leeflang, P., Wernars, P., Thomashow, L.S., Laureijs, E., Thomas-Oates, J.E., Bakker, P.A.H.M., and van Loon, L.C. 2001. Effect of genetically modified Pseudomonas putida WCS358r on the fungal rhizosphere microflora of field-grown wheat. Appl. Environ. Microbiol. 67: 3371-3378.

Handelsman, J., and Stabb, E.V. 1996. Biocontrol of soilborne plant pathogens. Plant Cell, 8: 1855-1869.

Heil, M. 2001. The ecological concept of costs of induced systemic resistance (ISR). Eur. J. Plant. Pathol. 107: 137-146.

Hoffland, E., Pieterse, C.M.J., Bik, L., and Van Pelt, J.A. 1995. Induced systemic resistance in radish is not associated with accumulation of pathogenesis-related proteins. Physiol. Mol. Plant Pathol. 46: 309-320.

Höfte, M. 1993. Classes of microbial siderophores. In Iron chelation in plants and soil microorganisms. Edited by L.L. Barton and B.C. Hemming. Academic Press, San Diego, Calif. pp. 3-26.

King, E.O., Ward, M.K., and Raney, D.E. 1954. Two simple media for demonstration of pyocyanin and fluorescin. J. Lab. Clin. Med. 44: 301-307.

Leeman, M., Van Pelt, J.A., Den Ouden, F.M., Heinsbroek, M., Bakker, P.A.H.M., and Schippers, B. 1995. Induction of systemic resistance against fusarium wilt of radish by lipopolysaccharides of Pseudomonas fluorescens. Phytopathology, 85: 1021-1027.

Leeman, M., Den Ouden, F.M., Van Pelt, J.A., Dirkx, F.P.M., Steijl, H., Bakker, P.A.H.M., and Schippers, B. 1996. Iron availability affects induction of systemic resistance to Fusarium 
wilt of radish by Pseudomonas fluorescens. Phytopathology, 86: 149-155.

Loper, J.E., and Buyer, J.S. 1991. Siderophores in microbial interactions on plant surfaces. Mol. Plant-Microbe Interact. 4: 5-13.

Lugtenberg, B.J.J., Dekkers, L., and Bloemberg, G.V. 2001. Molecular determinants of rhizosphere colonization by Pseudomonas. Annu. Rev. Phytopathol. 39: 461-490.

Maurhofer, M., Keel, C., Schnider, U., Voisard, C., Haas, D., and Défago, G. 1992. Influence of enhanced antibiotic production in Pseudomonas fluorescens strain CHA0 on its disease suppressive capacity. Phytopathology, 82: 190-195.

Maurhofer, M., Reimmann, C., Schmidli-Sacherer, P., Heeb, S., Haas, D., and Défago, G. 1998. Salicylic acid biosynthetic genes expressed in Pseudomonas fluorescens strain P3 improve the induction of systemic resistance in tobacco against tobacco necrosis virus. Phytopathology, 88: 678-684.

Mazzola, M., Fujimoto, D.K., Thomashow, L.S., and Cook, R.J. 1995. Variation in sensitivity of Gaeumannomyces graminis to antibiotics produced by fluorescent Pseudomonas spp., and effect on biological control of take-all of wheat. Appl. Environ. Microbiol. 61: 2554-2559.

Mercado-Blanco, J., Van der Drift, K.M.G.M., Olsson, P., ThomasOates, J.E., van Loon, L.C., and Bakker, P.A.H.M. 2001. Analysis of the pmsCEAB gene cluster involved in biosynthesis of salicylic acid and the siderophore pseudomonine in the biocontrol strain Pseudomonas fluorescens WCS374. J. Bacteriol. 183: 1909-1920.

Pieterse, C.M.J., and van Loon, L.C. 1999. Salicylic acidindependent plant defence pathways. Trends Plant Sci. 4: 52-58.

Pieterse, C.M.J., Van Wees, S.C.M., Van Pelt, J.A., Knoester, M., Laan, R., Gerrits, H., Weisbeek, P.J., and van Loon, L.C. 1998. A novel signaling pathway controlling induced systemic resistance in Arabidopsis. Plant Cell, 10: 1571-1580.

Pieterse, C.M.J., Van Wees, S.C.M., Ton, J., Van Pelt, J.A., and van Loon, L.C. 2002 Signalling in rhizobacteria-induced systemic resistance in Arabidopsis thaliana. Plant Biol. (Stuttgart), 4: 535-544.

Raaijmakers, J.M., Leeman, M., Van Oorschot, M.M.P., Van der Sluis, I., Schippers, B., and Bakker, P.A.H.M. 1995. Doseresponse relationships in biological control of fusarium wilt of radish by Pseudomonas spp. Phytopathology, 85: 1075-1081.

Reitz, M., Oger, P., Meyer, A., Niehaus, K., Farrand, S.K., Hallman, J., and Sikora, R.A. 2002. Importance of the 0antigen, core-region and lipid A of rhizobial lipopolysaccharides for the induction of systemic resistance in potato to Globodera pallida. Nematology, 4: 73-79.

Schwyn, B., and Neilands, J.B. 1987. Universal chemical assay for the detection and determination of siderophores. Anal.
Biochem. 160: 47-56.

Sonnemann, I., Finkhaeuser, K., and Wolters, V. 2002. Does induced resistance affect the belowground community. Appl. Soil Ecol. 21: 179-185.

Sticher, L., Mauch-Mani, B., and Métraux, J.P. 1997. Systemic acquired resistance. Annu. Rev. Phytopathol. 35: 235-270.

Ton, J., Van Pelt, J.A., van Loon, L.C., and Pieterse, C.M.J. 2002. Differential effectiveness of salicylate-dependent and jasmonate/ ethylene-dependent induced resistance in Arabidopsis. Mol. Plant-Microbe Interact. 15: 27-34.

van Loon, L.C., Bakker, P.A.H.M., and Pieterse, C.M.J. 1998. Systemic resistance induced by rhizosphere bacteria. Annu. Rev. Phytopathol. 36: 453-483.

Van Peer, R., and Schippers, B. 1992. Lipopolysaccharides of plant-growth promoting Pseudomonas sp. strain WCS417r induce resistance in carnation to fusarium wilt. Neth. J. Plant Pathol. 98: 129-139.

Van Peer, R, Niemann, G.J., and Schippers, B. 1991. Induced resistance and phytoalexin accumulation in biological control of Fusarium wilt of carnation by Pseudomonas sp. strain WCS417r. Phytopathology, 81: 728-734.

Van Wees, S.C.M., Pieterse, C.M.J., Trijssenaar, A., Van't Westende, Y.A.M., Hartog, F., and van Loon L.C. 1997. Differential induction of systemic resistance in Arabidopsis by biocontrol bacteria. Mol. Plant-Microbe Interact. 10: 716-724.

Van Wees, S.C.M., Luijendijk, M., Smoorenburg, I., van Loon, L.C., and Pieterse, C.M.J. 1999. Rhizobacteria-mediated induced systemic resistance (ISR) in Arabidopsis is not associated with a direct effect on expression of known defense-related genes but stimulates the expression of the jasmonate-inducible gene Atvsp upon challenge. Plant Mol. Biol. 41: 537-549.

Van Wees, S.C.M., De Swart, E.A.M., Van Pelt, J.A., van Loon, L.C., and Pieterse, C.M.J. 2000. Enhancement of induced disease resistance by simultaneous activation of salicylate- and jasmonate-dependent defense pathways in Arabidopsis thaliana. Proc. Natl. Acad. Sci. U.S.A. 97: 8711-8716.

Wei, G., Kloepper, J.W., and Tuzun, S. 1991. Induction of systemic resistance of cucumber to Colletotrichum orbiculare by select strains of plant growth-promoting rhizobacteria. Phytopathology, 81: 1508-1512.

Weller, D.M., Raaijmakers, J.M., McSpadden Gardener, B.B., and Thomashow, L.S. 2002. Microbial populations responsible for specific soil suppressiveness to plant pathogens. Annu. Rev. Phytopathol. 40: 309-348.

Whitman, W.B., Coleman, D.C., and Wiebe, W.J. 1998. Prokaryotes: The unseen majority. Proc. Natl. Acad. Sci. U.S.A. 95: 6578-6583. 